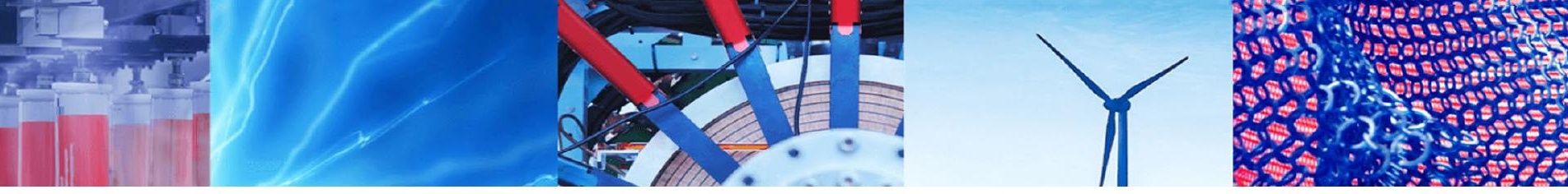

Research Article

\title{
Production of oxalic acid from sawdust using coal fly ash as a catalyst
}

\author{
O. Kuipa' ${ }^{1}$ G. Kasungasunge ${ }^{1}$ P. K. Kuipa ${ }^{2}$ (I)
}

Received: 6 July 2021 / Accepted: 28 September 2021

Published online: 09 October 2021

(c) The Author(s) 2021 OPEN

\begin{abstract}
The production of oxalic acid from sawdust using a mixture of strong nitric acid and concentrated sulphuric acid with coal fly ash as a catalyst has been explored. Operating parameters affecting the reaction were determined to be temperature, mesh size and amount of fly ash catalyst, time and the $\mathrm{HNO}_{3}: \mathrm{H}_{2} \mathrm{SO}_{4}$ ratio. A maximum oxalic acid yield of $84 \%$ was obtained using a mixture of $60 \% \mathrm{HNO}_{3}$ and $40 \% \mathrm{H}_{2} \mathrm{SO}_{4}$ at $70{ }^{\circ} \mathrm{C}$ and a reaction time of 150 minutes. Coal fly ash with particle size of 50-100 $\mu \mathrm{m}$ proved to be a suitable and efficient catalyst, and the optimum quantity of catalyst employed was $5 \mathrm{~g}$ of fly ash for every $100 \mathrm{~g}$ of sawdust.
\end{abstract}

Keywords Oxalic acid $\cdot$ Sawdust $\cdot$ Nitric acid $\cdot$ Fly ash $\cdot$ Sulphuric acid $\cdot$ Operating parameters

\section{Introduction}

Sawdust is a waste by-product emanating from sawmills, wood furniture factories and carpentries. Sawdust poses significant risk such as fire, air pollution and the proliferation of vermin in the environment. Various opportunities are available to valorize sawdust waste and increase the business competitiveness of the timber and wood furniture industry value chain. In agriculture, sawdust is used as a mulch, soil conditioner and as a substrate for growing edible mushrooms. Sawdust is also used for the manufacture of chipboard panels and for the production of pellets for use in fuel boilers and as an additive in concrete and brick manufacturing [1]. Several investigations have shown that lignocellulosic materials such as sawdust may be used as raw materials for the production of oxalic acid, an industrially important chemical with various applications in the paper, leather and mineral extraction industries [2].

Oxalic acid is a reducing agent and has been used as an analytical reagent and standard, a wood bleach, a metal polish, and a metal precipitating or chelating agent [3]. In the textile industry, it is employed as a stain remover and mordant and may also be used to remove calcium in water treatment applications [4]. Oxalic acid has been employed as an environmental control agent for ticks [5] and for the control of varroosis (a disease caused by the parasitic mite, Varroa destructor) during honey bee production [6]. Reimenshneider and Tanifuji [7] categorized the principal applications of oxalic acid as approximately 28 per cent metal treatment, 25 per cent textile treatment, 20 per cent bleaching agents and 27 per cent chemical uses.

Sawdust is made up of three structural polymers: cellulose, hemicellulose and lignin [8]. The first two

$\triangle$ P. K. Kuipa, kuipapardon@yahoo.com | 'Department of Chemical Engineering, National University of Science and Technology, Bulawayo, Zimbabwe. ${ }^{2}$ Lupane State University, Lupane, Zimbabwe.

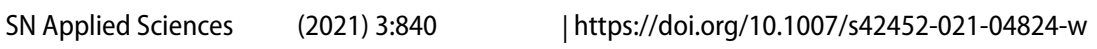


components are carbohydrates, whilst the latter is an amorphous and complex three-dimensional polyphenolic polymer that is composed largely of repeating phenyl propane-based monolignol sub-units, with either p-hydroxyphenyl $(H)$, guaiacyl $(G)$ or syringyl $(S)$ units predominating. These units are connected through various ether and carbon-carbon bonds. Syringyl structural units are more stable than the guaiacyl units because the former cannot undergo condensation involving the unsubstituted fifth carbon atom in the benzene ring [9]. Lignin with a higher content of methoxy groups ( $\mathrm{S}>\mathrm{G}>\mathrm{H}$ ) contains a lower fraction of chemically resistant carbon-carbon bonds and is therefore more susceptible to extensive depolymerization under hydrolysis conditions [10]. Hardwood lignin typically contains a higher amount of ether bonds than softwood lignin, and consequently, hardwoods are generally easier to hydrolyse than softwoods [11]. Generally, softwoods consist of $45-50 \%$ cellulose, $25-35 \%$ hemicellulose and $25-35 \%$ lignin, whilst hardwoods consist of $40-55 \%$ cellulose, $24-40 \%$ hemicellulose and $18-25 \%$ lignin [12]. Softwoods contain more lignin than hardwoods.

Native lignin is readily susceptible to oxidizing agents and may, under the right conditions, be converted to valuable chemicals such as vanillin, oxalic acid and other acids such as the dicarboxylic and aldonic acids $[13,14]$. Generally, the use of strong oxidizing agents such as nitric acid breaks up the aromatic ring, whereas milder oxidizing agents such as nitrobenzene cause changes in the side chain whilst keeping the ring intact [15]. Hemicellulose is a hetero-polysaccharide that is composed of different sugar units and is readily broken down by mild treatments with acid. Cellulose, on the other hand, is a homo-polysaccharide which is partially crystalline and consists of glucose units linked to each other via $\beta$-1,4-glucosidic bonds and inter- and intra-molecular hydrogen bonds. It is generally more difficult to depolymerize cellulose than hemicellulose. The residue that remains after treatment of the sawdust with a mixture of strong nitric acid and concentrated sulphuric acid is probably composed of insoluble residual lignin, together with oxy-cellulose and hydro-cellulose, which are known to be degradation products of cellulose oxidation and to be more resistant to oxidation than the original cellulose $[16,17]$.

When cellulose or hemicellulose is exposed to a mixture of concentrated sulphuric acid and nitric acid, the sulphuric acid, due to its strong acidity, is thought to mediate the initial hydrolysis steps [18]. The initial hydrolysis steps result in the depolymerization and solubilization of the polysaccharides due to the formation of hexose sugars (mainly, glucose) from cellulose and a mixture of hexose and pentose sugars (mainly, glucose, xylose and arabinose) from hemicellulose [19]. On the other hand, the reaction between lignin and nitric acid is a complex process in which the nitric acid participates in both electrophilic nitration and oxidation reactions with the lignin [20]. Nitration that is an electrophilic substitution reaction of hydrogen atoms of the benzene ring of the phenylpropanoic unit proceeds rapidly due to the presence of activating electron-donating groups [21]. The nitration is accompanied by oxidation not only of the propanoic chains but also the aromatic rings [22].

During the oxidation of lignin and polysaccharides by nitric acid, the reactions are mediated by a complex nitrogen redox cycle (slow self-decomposition of nitric acid) that interconverts nitrogen from its highest oxidation state to the reactants' nitrous acid and nitrogen dioxide [23]. Nitrogen dioxide fuels the autocatalytic reaction between nitric acid and polysaccharides, through its reaction with water to form more nitrous acid and nitric acid. Nitrous acid carries out the substrate oxidation for the polysaccharides and also accounts for the autocatalytic characteristics of lignin oxidation by facilitating intermediate nitration reactions, methoxyl cleavage, and the oxidation and ring opening of quinones and quinoid intermediate products to the final reaction products $[24,25]$.

Weber [26] reported that the evolving gases that are excess to the stoichiometric oxidation reaction requirements may be absorbed rapidly and completely in concentrated sulphuric acid ( 85 to $95 \% \mathrm{v} / \mathrm{v}$ ), to form nitrosyl sulphuric acid, in accordance with the following reactions:

$\mathrm{NO}+\mathrm{NO}_{2} \rightarrow \mathrm{N}_{2} \mathrm{O}_{3}$

$\mathrm{N}_{2} \mathrm{O}_{3}+2 \mathrm{H}_{2} \mathrm{SO}_{4} \rightarrow 2 \mathrm{OH} \cdot \mathrm{SO}_{2} \cdot \mathrm{ONO}+\mathrm{H}_{2} \mathrm{O}$

$2 \mathrm{NO}_{2} \rightarrow \mathrm{N}_{2} \mathrm{O}_{4}$

$\mathrm{N}_{2} \mathrm{O}_{4}+\mathrm{H}_{2} \mathrm{SO}_{4} \mathrm{OH} \cdot \mathrm{SO}_{2} \cdot \mathrm{ONO}+\mathrm{HNO}_{3}$

When nitric acid functions as an oxidizing agent, water is one of the products of the reaction. In order to prevent the dilution of the remaining nitric acid and thus decreasing the efficiency of the nitric acid as an oxidizer, concentrated sulphuric acid plays a further role as a dehydrating agent, by removing the water as fast as it is formed.

A number of catalysts can be employed so that one of the competing reactions, i.e. the formation of oxalic acid, during the oxidation of polysaccharides by nitric acid becomes the dominant and target reaction. The use of vanadium pentoxide, molybdic oxide, mixture of vanadium pentoxide and molybdic oxide, tungstic acid and titanic acid as the catalyst, which provides the desired selectivity, has been reported [27-29].

Coal fly ash consists of incombustible inorganic materials that are found in coal, which are fused during the 
combustion process to form a glassy amorphous material that has silica as the principal constituent. A small fraction of fly ash is used in the cement, concrete and the brick manufacturing industries, but the bulk of fly ash is commonly disposed of as landfill, thereby causing environmental pollution [30, 31]. Kanti et al. [32, 33] have reported the use of fly ash to manufacture water-based nanofluids, which have been proposed as potential heat transfer media with superior heat transfer characteristics. A number of research studies have demonstrated that fly ash and its various modifications can be harnessed as an efficient catalyst for the synthesis of organic compounds under various conditions [34-36]. Brønsted and Lewis acidic sites and metal (particularly iron and calcium) oxide sites on the fly ash/modified fly ash catalyst are thought to be responsible for the catalytic activity. $\mathrm{CaO}$ is an active base catalyst and a promotor, whilst $\mathrm{Fe}_{2} \mathrm{O}_{3}$ is an active redox catalyst for a wide range of reactions, including Friedel-Crafts acylation [37]. The combination of Lewis and Brønsted acidic sites and redox sites provides by-functionality to the coal fly ash catalyst. Zhang et al. [38] reported that nitric acidactivated fly ash may be employed as a heterogeneous Fenton-like catalyst for $\mathrm{p}$-nitrophenol removal from water, with a removal rate of $98 \%$ being observed. Wang [39] also reported that fly ash may be used as an effective catalyst for the aqueous phase oxidation of organics.

The purpose of this study was to determine the optimum conditions at which the maximum yield of oxalic acid can be obtained during nitric acid oxidation of sawdust in the presence of concentrated sulphuric acid, when fly ash is employed as the catalyst. The experiments involved the hydrolysis and oxidation of sawdust using a mixture of concentrated sulphuric acid and strong nitric acid and separation of oxalic acid from the reaction liquor through crystallization. The rest of the article is organized as follows: Section 2 describes the experimental methods employed by the authors. Section 3 reports the results and provides a discussion of the results. Section 4 concludes the research study and provides useful comments on future works.

\section{Experimental}

\subsection{Materials and method}

Pine tree (a softwood) sawdust was collected from a local carpentry shop, washed and sun-dried for 48 hours to reduce the water content after which it was ground to reduce the particle size to less than $5 \mathrm{~mm}$. Coal fly ash was collected from a local company. The coal fly ash was screened to remove the coarse materials and unburnt coal particles. The chemical composition of coal fly ash from the same local company as in this study was previously reported [40] to be $40.92 \% \mathrm{SiO}_{2}, 31.91 \% \mathrm{Al}_{2} \mathrm{O}_{3}, 11.02 \%$ $\mathrm{Fe}_{2} \mathrm{O}_{3}, 6.10 \% \mathrm{CaO}$ and other trace metal oxides such as $\mathrm{MgO}, \mathrm{TiO}_{2}, \mathrm{MnO}, \mathrm{Na}_{2} \mathrm{O}, \mathrm{K}_{2} \mathrm{O}, \mathrm{SO}_{3}$ and $\mathrm{P}_{2} \mathrm{O}_{5}$. Two particle grind size ranges were used: $1-5 \mathrm{~mm}$ and $50-100 \mu \mathrm{m}$.

The $56.5 \% \mathrm{v} / \mathrm{v} \mathrm{HNO}_{3}$ was obtained from a local nitrate fertilizer manufacturer, which produces nitric acid as a reactant in the production of ammonium nitrate fertilizer. $95 \% \mathrm{v} / \mathrm{v} \mathrm{H}_{2} \mathrm{SO}_{4}$ was obtained from a local phosphate fertilizer manufacturer, which manufactures sulphuric acid from local pyrites. A $1000-\mathrm{mL}$ beaker was used for the experiments.

All other chemicals were of analytical reagent grade and were obtained from Sigma-Aldrich. For experiments in which the amount of sawdust was not a variable, $100 \mathrm{~g}$ of sawdust was used. Appropriate ratios of $\mathrm{H}_{2} \mathrm{SO}_{4}$ and $\mathrm{HNO}_{3}(\mathrm{v} / \mathrm{v})$ were measured and emptied into the beaker. The total volume of the two acids in each experiment was $500 \mathrm{ml}$. The contents were placed on a heating surface, and the temperature increased to the desired reaction temperature as measured by a thermometer inside the beaker. The thermometer was also used to stir the mixture. The reaction was terminated when the brown $\mathrm{NO}_{x}$ gases became light or pale yellow in colour. The reaction mixture at this stage was cooled to 0 ${ }^{\circ} \mathrm{C}$ first by running a stream of tap water on the outside of the beaker and then placing the beaker in a freezer. $\mathrm{C}_{2} \mathrm{H}_{2} \mathrm{O}_{4}$ crystals formed were separated through filtration using Whatman filter paper. The filtrate was heated at $50{ }^{\circ} \mathrm{C}$ for ten minutes before being cooled again to $0^{\circ} \mathrm{C}$ and filtered again to yield a lesser quantity of oxalic acid crystals.

The $\mathrm{C}_{2} \mathrm{H}_{2} \mathrm{O}_{4}$ crystals from each experimental run were combined and dissolved in water at $80^{\circ} \mathrm{C}$ and the solution stirred vigorously. The solution was then cooled in the same manner as above and filtered to obtain the purer crystals of $\mathrm{C}_{2} \mathrm{H}_{2} \mathrm{O}_{4}$ whose weight was used to calculate the yield. The above procedure was repeated for experimental runs at different reaction temperatures, acid ratios, reaction times, mass of catalyst and catalyst size. In another range of experiments, $5 \mathrm{~g}$ of manganese metal powder ( $99.5 \%$ purity) from Sigma-Aldrich [Tyler Standard Screen -325 mesh $(-0.044 \mathrm{~mm})]$ was used as the catalyst in order to compare its activity with that of fly ash. The manganese powder was used as received. 


\subsection{Determination of Oxalic Acid Yield}

For each combination of variables, three separate experiments were carried out. The crystals obtained were dried at $65^{\circ} \mathrm{C}$ and weighed. An average mass for each combination was obtained as follows: approx. $50 \%$ was obtained at $70{ }^{\circ} \mathrm{C}$ for the $60 \%: 40 \%$ acid ratio. Increase in temperature beyond $70^{\circ} \mathrm{C}$ was accompanied by a gradual decrease in yield. Decomposition of oxalic acid into water and carbon dioxide occurs at higher temperatures, resulting in a decreased yield. Other studies have reported optimum temperatures in the range 58-75

Average mass of $\mathrm{C}_{2} \mathrm{H}_{2} \mathrm{O}_{4}=\frac{\text { Mass (1 st experiment) }+ \text { Mass (2nd experiment) }+ \text { Mass (3rd experiment) }}{3}$

The yield of oxalic acid was calculated as follows:

Yield $=\frac{\text { Average mass of } \mathrm{C}_{2} \mathrm{H}_{2} \mathrm{O}_{4} \text { produced (grams) }}{100 \mathrm{~g}(\text { of sawdust used })} \times 100$

\section{Results and discussion}

\subsection{Effect of Temperature}

The first batch of experiments were carried out in the absence of any catalyst and served to determine the optimum temperature for the maximum yield of $\mathrm{C}_{2} \mathrm{H}_{2} \mathrm{O}_{4}$. The results are presented in Figure 1. The yield increased with temperature for each acid ratio, and the maximum yield of

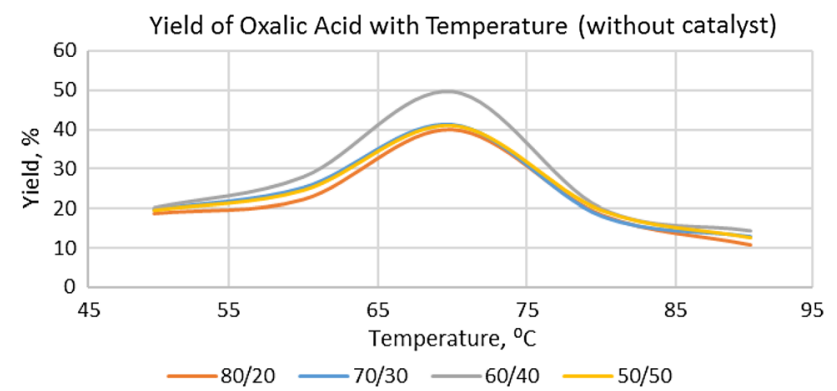

Fig. 1 Yield of oxalic acid at different temperatures using different acid ratios
${ }^{\circ} \mathrm{C}$ depending on the carbohydrate used [41, 42]. An optimum temperature is characteristic of hexose and pentose sugar oxidation reactions, which are essentially exothermic [43]. The redox reactions that interconvert nitrogen from its highest formal oxidation state into the reactants nitrous acid and nitrogen dioxide are also exothermic. All experiments in which temperature was constant were conducted at $70^{\circ} \mathrm{C}$.

\subsection{Effect of the amount of $\mathrm{H}_{2} \mathrm{SO}_{4}$ added on the yield of oxalic acid}

The effect of the amount of $\mathrm{H}_{2} \mathrm{SO}_{4}$ per $100 \mathrm{~g}$ of sawdust on the yield of oxalic acid was studied. The density of $\mathrm{H}_{2} \mathrm{SO}_{4}$ used at $25^{\circ} \mathrm{C}$ was $1.8286 \mathrm{~g} / \mathrm{cm}^{3}$. Figure 2 shows the effect of the mass of $\mathrm{H}_{2} \mathrm{SO}_{4}$ added on the yield of oxalic acid. The yield increased steadily with mass of $\mathrm{H}_{2} \mathrm{SO}_{4}$ until a maximum oxalic acid yield of $84 \%$ was obtained with $3.66 \mathrm{~g}$ of $\mathrm{H}_{2} \mathrm{SO}_{4}$ per gram of sawdust. Any further increase in the mass of the acid resulted in a decrease in yield. The decrease in yield may also be attributed to the fact that dissolution of hemicellulose and cellulose in aqueous sulphuric acid solutions at mild temperatures of 50 to $100^{\circ} \mathrm{C}$ is fast when the acid concentration is $\geq 65 \% \mathrm{v} / \mathrm{v}$ and when the acid to cellulose ratio is $>2 \mathrm{~mL} / \mathrm{g}[18,19]$. The initial dissolution step is followed by hydrolysis of the solubilized hemicellulose and cellulose to form pentoses and hexoses, which are then oxidized to oxalic acid by the strong nitric acid. The hydrolysis of hemicellulose is fast, whilst that for
Fig. 2 Effect of the amount of $\mathrm{H}_{2} \mathrm{SO}_{4}$ used on the oxalic acid yield

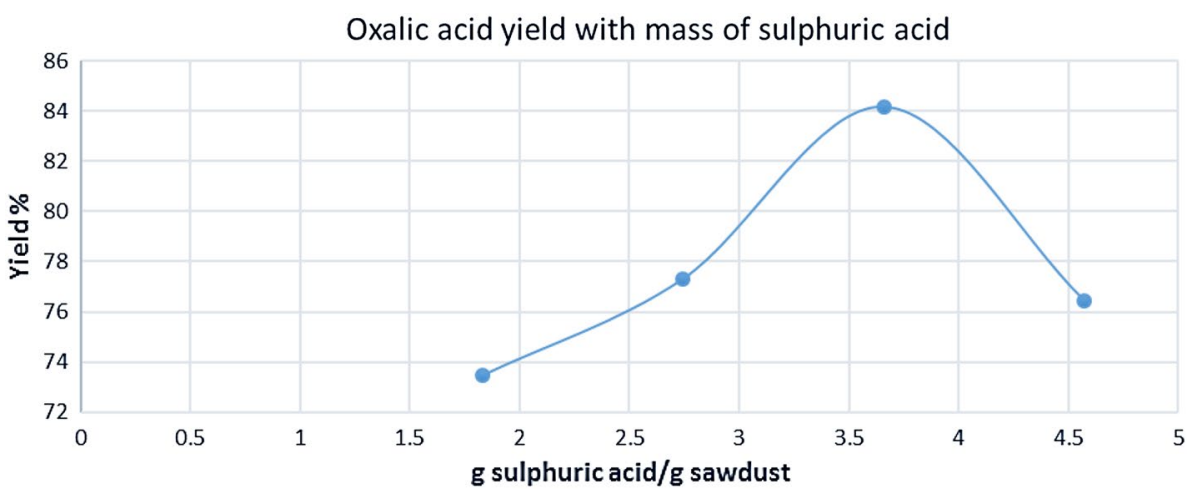


Fig. 3 The effect of different masses of fly ash on the yield of oxalic acid

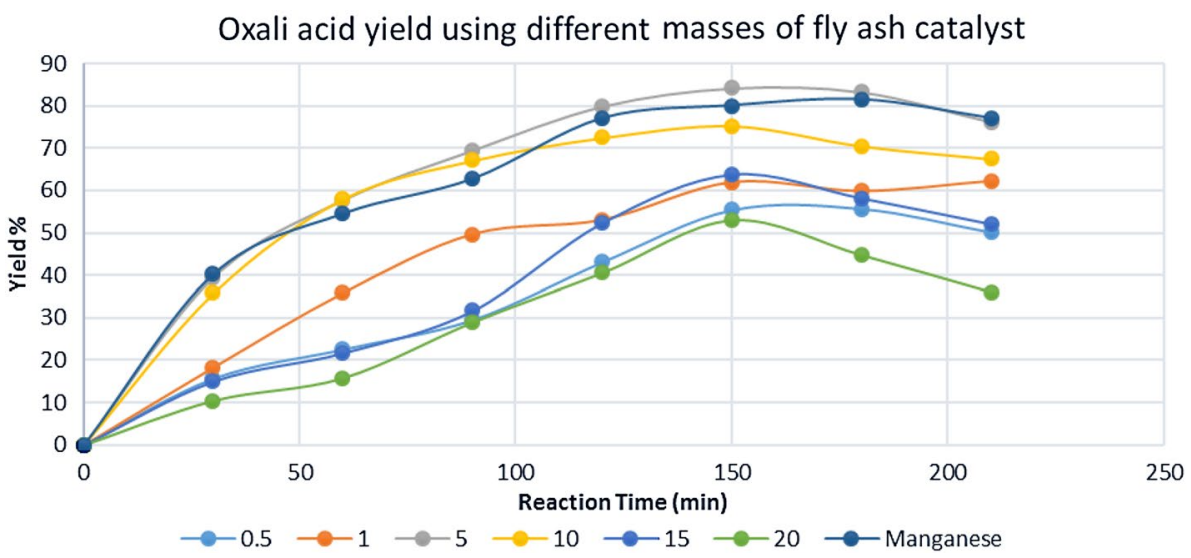

cellulose is slower [44]. On the other hand, lignin is unaffected by the sulphuric acid but is nitrated and oxidized by the strong nitric acid leading to the destruction of the benzene ring. Since $100 \mathrm{~g}$ of sawdust was used for the experiments, the amount of $\mathrm{H}_{2} \mathrm{SO}_{4}$ required was $366 \mathrm{~g}\left(200 \mathrm{~cm}^{3}\right)$, which corresponds to $40 \%(\mathrm{v} / \mathrm{v})$ in a $500-\mathrm{cm}^{3}$ mixture of $\mathrm{HNO}_{3}$ and $\mathrm{H}_{2} \mathrm{SO}_{4}$. For all subsequent experiments in which the acid ratio was a constant, a $60 / 40 \mathrm{v} / \mathrm{v}$ mixture of $\mathrm{HNO}_{3}$ and $\mathrm{H}_{2} \mathrm{SO}_{4}$ was employed.

\subsection{Effect of the amount of Fly Ash catalyst}

Six different masses of fly ash catalyst were used: $0.5,1$, $5,10,15$ and $20 \mathrm{~g}$, per 100 grams of sawdust. The yields obtained with time are given in Fig. 3. The yield for the different masses increased with time to a maximum after about 150 minutes and then slowly decreased thereafter. The highest yield of $84 \%$ was obtained using $5 \mathrm{~g}$ of fly ash. When larger amounts of fly ash were used, small amounts of wood oils and waxy substances were observed on the walls of the reactor, possibly due to the promotion of aldol condensation of monosaccharides to polysaccharides and the condensation of polysaccharides to humins and other oligosaccharides, leading to the formation of syrup-like by-products $[45,46]$. The formation of wood oils and waxy substances could also be due to the fact that lignin is prone to repolymerization reactions in the presence of acid or base catalysts [47]. The repolymerization products have low solubility in aqueous phases. In some instances during the oxidative depolymerization of lignins, reactive radicals may be formed that can lead to partial repolymerization of the soluble lignin leading to the formation of more complex lignin structures $[48,49]$. Brønsted basic sites are also present on the coal fly ash catalyst and may lead to the formation of base catalysed condensation products of monosaccharides at elevated temperatures. Consequently, an increase in the amount of catalyst leads to an increase in the conversion of substrate at the expense of a reduction in selectivity due to increased secondary reactions (disproportionation and over-oxidation reactions). The preceding speculations are based on the literature, given that individual side-reaction products of the hydrolysis and oxidation reactions were not isolated and analysed in this study.
Fig. 4 Yield of oxalic acid using coarse fly ash

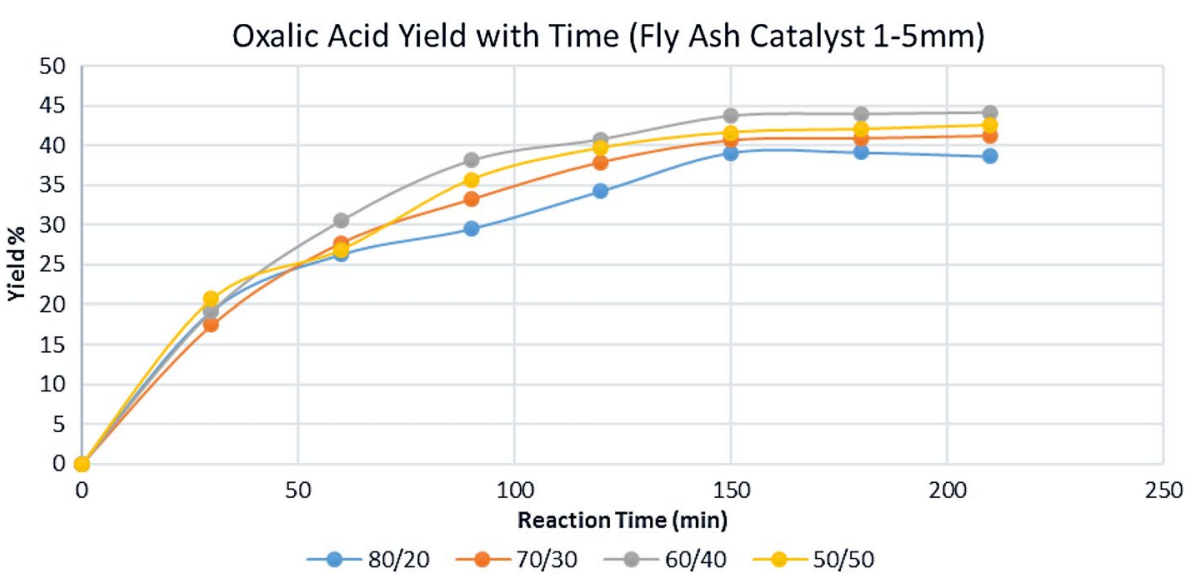

SN Applied Sciences 
Fig. 5 Yield of oxalic acid using fine fly ash

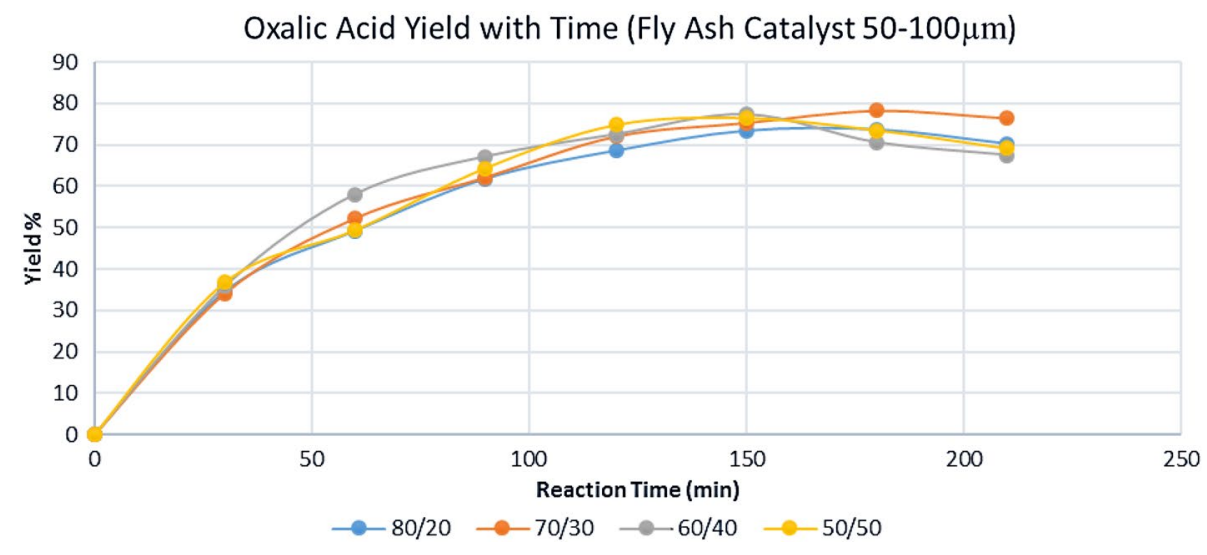

\subsection{Effect of Fly Ash particle size and reaction time}

The effect of the catalyst particle grind size (fine or coarse size) on the yield of $\mathrm{C}_{2} \mathrm{H}_{2} \mathrm{O}_{4}$ was also investigated. Ten grams of fly ash was used in each experiment. Two particle grind size ranges were used: $1-5 \mathrm{~mm}$ and $50-100 \mu$ $\mathrm{m}$. Figure 4 shows the yield of oxalic acid produced using the $1-5 \mathrm{~mm}$ grind size range. The results show that a maximum yield of $44 \%$ was obtained using $60 \% \mathrm{HNO}_{3}$ and $40 \% \mathrm{H}_{2} \mathrm{SO}_{4}$. The maximum yield for each acid ratio was obtained after 150 minutes. A further increase in the reaction time produced no significant increase in oxalic acid yield. This observation is also true when manganese metal catalyst was employed.

Figure 5 gives the yield obtained using fly ash with a size range of $50-100 \mu \mathrm{m}$. The yield of $\mathrm{C}_{2} \mathrm{H}_{2} \mathrm{O}_{4}$ increased with time until a maximum was reached after 150 minutes for each acid ratio.

The yield decreased beyond 150 minutes, the decrease being more pronounced for the $60 \%: 40 \%$ and 50\%:50\% acid ratios. The maximum yield obtained was 77\% for the 60\%:40\% acid ratio after 150 minutes. After 150 minutes, the fly ash catalyst may be promoting the decomposition of oxalic acid due to over-oxidation of the oxalic acid to carbon dioxide and water. The catalytic activity of the employed coal fly ash catalyst is strongly dependent on particle size possibly due to the abundance of low bond coordinated metal oxide atoms at the edges of the smaller catalyst particles, which, in the case of, for example, gold nanoparticles, have been reported to facilitate the adsorption of reactants and substrate, thus promoting faster product formation [50]. Generally, in catalytic processes involving gaseous, liquid and solid phases, only the catalyst grain outer surface area is primarily active. Therefore, the high catalyst surface area necessary for a good yield of the products can only be practically achieved by decreasing the catalyst grain size, this being equivalent to an increase in the total surface area available for the reaction. The observed decrease in yield after 150 minutes could be due to the promotion of competing side reactions, or deactivation of the catalyst by poisoning due to the adsorption of the formed products. If the active sites are at the surface of the catalyst particles, then the chemisorption of products formed could block active sites and cause deactivation. Additionally, deactivation can be caused by metal leaching in the hot acidic environment leading to a decrease in catalytic activity.
Fig. 6 Yield of oxalic acid with time using different acid ratios and manganese metal

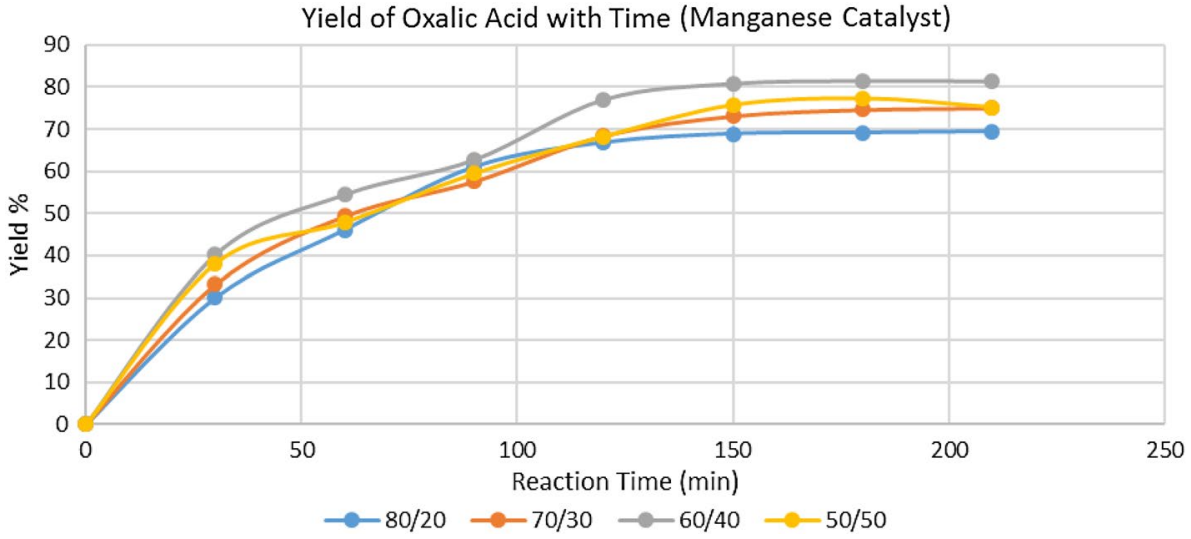


Fig. 7 Effect of reaction time on oxalic acid yield

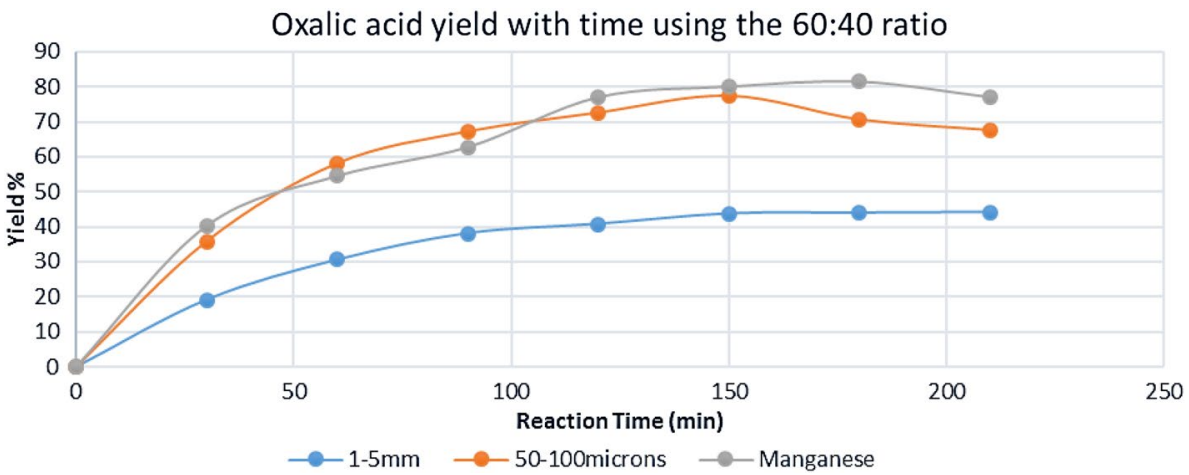

Table 1 Proposed conditions for the nitric acid oxidation of sawdust with fly ash as catalyst.

\begin{tabular}{|c|c|}
\hline Operating parameter & Value \\
\hline Reaction temperature & $70^{\circ} \mathrm{C}$ \\
\hline Reaction time & 150 minutes ( 2.5 hours) \\
\hline \multicolumn{2}{|l|}{ Catalyst } \\
\hline Particle size & $50-100 \mu \mathrm{m}$ \\
\hline Mass & $0.05 \mathrm{~g}$ fly $\mathrm{ash} / \mathrm{g}$ of sawdust \\
\hline Sulphuric acid & $3.66 \mathrm{~g} \mathrm{H}_{2} \mathrm{SO}_{4} / \mathrm{g}$ of sawdust \\
\hline Nitric acid & $4.03 \mathrm{~g} \mathrm{HNO}_{3} / \mathrm{g}$ of sawdust \\
\hline
\end{tabular}

The maximum yield with both particle size ranges was obtained using the same acid ratio, $60 \% \mathrm{HNO}_{3}$ and $40 \% \mathrm{H}_{2} \mathrm{SO}_{4}$.

\subsection{Effect of Manganese as a Catalyst}

A batch of experiments was run with manganese metal as the catalyst so as to compare the performance with that of fly ash catalyst. The results are given in Fig. 6 .

The maximum yield obtained was $81 \%$ for the $60 \%: 40 \%$ acid ratio. Maximum yields in the range $79-82 \%$ have been reported using manganese metal catalyst [42]. The maximum yield for each acid ratio was obtained after 150 minutes, and any further increase in time produced no significant increase in the oxalic acid yield.

In Fig. 7, the yield for two size ranges is compared with that of manganese for the $60 \%: 40 \%$ acid ratio.

Figure 7 indicates that a higher yield was obtained for fine fly ash particles compared to coarse fly ash particles, with a maximum difference in yield of almost $40 \%$. The results also indicate the applicability of fly ash as a catalyst in the reaction with results resembling those for manganese metal. The finer the particles, the greater the surface area for adsorption of the reacting molecules, and a decrease in the activation energy is needed for the reaction to proceed. A higher yield was obtained with finer fly ash due to the increased surface area for the reaction rate.

\section{Summary of the proposed operating conditions}

The conditions that were varied during the nitric acid oxidation of sawdust were: $\mathrm{HNO}_{3}: \mathrm{H}_{2} \mathrm{SO}_{4}$ ratio, reaction temperature, size and quantity of fly ash catalyst, and reaction time. The proposed operating conditions for the reaction are summarized in Table 1 . The corresponding yield given by these conditions is $84 \%$ oxalic acid. Literature values of oxalic acid yield using sawdust under similar conditions as in this study vary widely from 80.2 [36] to $60 \%$ [51].

\section{Conclusion}

Nitric acid oxidation of sawdust was carried out in this study in order to ascertain the feasibility of using fly ash as a catalyst in the process. Fly ash, a relatively inexpensive and benign material, is a suitable and efficient catalyst for the oxidation reaction with results similar to those obtained when using a manganese metal catalyst. A maximum yield of $84 \%$ oxalic acid was obtained after 150 minutes and at $70^{\circ} \mathrm{C}$ using for every gram of sawdust; $0.05 \mathrm{~g}$ fly ash with particle size range $50-100 \mu \mathrm{m}$, $3.66 \mathrm{~g} \mathrm{H}_{2} \mathrm{SO}_{4}$ and $4.03 \mathrm{~g} \mathrm{HNO}_{3}$. The oxalic acid obtained had physical properties similar to those stated in the literature.

Sawdust and fly ash are cheap raw materials that are locally available, and their utilization may provide a costeffective and environmentally friendly way of recycling these wastes, thereby significantly reducing their environmental footprint. Valorizing sawdust has the potential to contribute to economic growth in remote parts of most developing countries where timber sawmills are normally located. More research shall be required in order to investigate the performance and long-term stability of the catalyst, since fly ash contains trace elements such as mercury, which may be released during fly ash catalyst utilization, 
thus causing secondary pollution. Additionally, characterization of the different side-reaction products will be required.

\section{Declarations}

Conflict of interest The authors declare that they have no conflict of interest.

Open Access This article is licensed under a Creative Commons Attribution 4.0 International License, which permits use, sharing, adaptation, distribution and reproduction in any medium or format, as long as you give appropriate credit to the original author(s) and the source, provide a link to the Creative Commons licence, and indicate if changes were made. The images or other third party material in this article are included in the article's Creative Commons licence, unless indicated otherwise in a credit line to the material. If material is not included in the article's Creative Commons licence and your intended use is not permitted by statutory regulation or exceeds the permitted use, you will need to obtain permission directly from the copyright holder. To view a copy of this licence, visit http://creativecommons. org/licenses/by/4.0/.

\section{References}

1. Chemani B, Chemani H (2012) Effect of adding sawdust on mechanical-physical properties of ceramic bricks to obtain lightweight building material. Int J Mech Mechatr Eng 6:2521-2525

2. Jiang Z, Zhang Z, Song J, Meng Q, Zhou H, He Z, Han B (2016) Metal oxide catalyzed efficient conversion of cellulose to oxalic acid in alkaline solution under low oxygen pressure. ACS Sustainable Chem Eng 4(1):305-311

3. Walter W (1996) 2.34 Saturated aliphatic dicarboxylic acids. In: Handbook of Organic Chemistry, pp 323-326. Hertfordshire, England: Prentice Hall Europe

4. Vishwakarma RS, Gogate PR (2011) Intensified oxalic acid crystallization using ultrasonic reactors: understanding effect of operating parameters and type of ultrasonic reactor. Ultrason Sonochem 39:111-119

5. Valcárcel F, Peréz Sánchez JL, Tercero Jaime JM, Basco-Basco PI, Guajardo SC, Cutuli MT, Martín-Hernández R, Olmeda AS (2014) Control of host-seeking adults of hyalomma lusitanicum with oxalic acid under field conditions. Int J Veterinary Med: Res Reports. https://doi.org/10.5171/2014871622

6. Rosenkranz P, Aumeier P, Ziegelmann B (2010) Biology and control of Varroa destructor. J Invertebr Pathol 103:96-119

7. Riemenschneider W, Tanifuji M (2011) Oxalic acid. In Ullmann's encyclopedia of industrial chemistry. Wiley-VCH Verlag \& Co, Germany

8. Roth J, Tippkotter N (2016) Evaluation of lignocellulosic material for butanol production using enzymatic hydrolysate medium. Cellulose Chem Technol 50(3-4):405

9. Tarabanko VE, Koropatchinskaya NV, Kudryashev AV, Kuznetsov BN (1995) Influence of lignin origin on the efficiency of the catalytic oxidation of lignin into vanillin and syringaldehyde. Russian Cheml Bull 2:367-371

10. Laskar DD, Yang B, Wang H, Lee J (2013) Pathways for biomassderived lignin to hydrocarbon fuels. Biofuels Bioprod Bioref 7:602-626
11. Rinaldi R, Jastrzebski R, Clough MT, Kennema JRM, Bruijnincx PCA, Weckhuysen BM (2016) Paving the way for lignin valorization: recent advances in bioengineering, biorefining and catalysis. Angewandte Chemie 55(29):8164-8215

12. Harmsen PFH, Huijgen WJJ, Bermúdez López LM, Bakker RRC (2010) Literature Review of Physical and Chemical Pretreatment Processes for Lignocellulosic Biomass. Bioenergy Project, Report 1184, Energy Research Centre of Netherlands (ECN), Wageningen

13. Schutyser W, Renders T, Van den Bosch S, Koelewijn SF, Beckham GT (2018) Chemicals from lignin: an interplay of lignocellulose fractionation, depolymerisation and upgrading. Chem Soc Rev 47(3):852-908

14. Sun Z, Fridrich B, de Santi A, Elangovan S, Barta K (2018) The bright side of lignin depolymerization: towards new platform chemicals. Chem Rev 118(2):614-678

15. Moodley B, Mulholland DA, Brookes HC (2012) The chemical oxidation of lignin found in Sappi Saicoor dissolving pulp mill effluent. Water SA 38(1):1-7

16. Bouchard J, Abatzoglou N, Chornet E, Overend RP (1989) Characterization of depolymerized cellulosic residues. Part 1: residues obtained by acid hydrolysis processes. Wood Sci Technol 23:343-355

17. Feller RL, Lee SB, Bogaard J (1986) The kinetics of cellulose deterioration, Advances in Chemistry, 212, Eds: Needles HL, Zeronian SH, ACS Publications, Chapter 18, pp. 329-347

18. Verendel JJ, Church TL, Andersson PG (2011) Catalytic one-pot production of small organics from polysaccharides. Synthesis 11:1649-1677

19. Camacho F, Gonzalez-Tello P, Jurado E, Robles A (1996) Microcrystalline-cellulose hydrolysis with concentrated sulphuric acid. J Chem Technol Biotechnol 67:350

20. Tarabanko VE, Tarabanko N (2017) Catalytic oxidation of lignins into aromatic aldehydes: general process trends and development prospects. Int J Mol Sci 18(11):2421

21. Chen $Q$, Xiao S, Shi SQ, Cai $L$ (2018) Isolation of cellulose from poplar wood by nitric acid-ethanol treatment and its effect on the quality of films cast from ionic liquid. BioResources 13(4):8943-8955

22. Khabarov YuG, Lakhmanov DE, Kosyakov DS, Ul'yanovskii NV, (2016) Studies of reaction products of hydrolytic lignin with nitric acid. Russian Chem Bull Int Edition 65(1):237-244

23. Somma ID, Marotta R, Andreozzi R, Caprio V (2014) Nitric acid decomposition kinetics in mixed acid and their use in the modelling of aromatic nitration. Chem Eng Trans 36:127

24. Sergeeva LL, Shorygina NN, Lopatin BV (1964) Nitration of the lignin model compounds 3-(3,4-dimethoxyphenyl)-1-propanol and 3-(4-hydroxy-3-methoxyphenyl)-1-propanol. Izvestiya Akademii Nauk USSR Seriya Chemicheskaya 7:1254-1260

25. Sobolev I (1961) Lignin model compounds. Nitric acid oxidation of 4-methylguaiacol. J Organic Chem 26(12):5080-5085

26. Webber HA (1929) I. Studies on the production of oxalic acid from corn stalks and cobs; Il. Studies on corn stalk cellulose. Retrospective Theses and Dissertations:14695. lowa State University, https://lib.dr.iastate.edu/rtd/14695

27. Guru V, Pamuk V, Bilgesu AY (2002) Production of oxalic acid from sugar beet molasses by mixed nitric acid and sulphuric acid. Cellulose Chem Technol 36(1):81-91

28. Han Y, Zhang J, Liu X (2014) Molybdenum containing acidic catalysts to convert cellulosic biomass to glycolic acid. US Patent 8846974 B2

29. Li Z, Zhang J, Hou B, Wang A (2019) Kinetic study of cellulose hydrolysis with tungsten-based acid catalysts. Reaction Eng Kinet Catalysis: AIChE J 65(6):e16585 
30. Kanti P, Sharma KV, Ramachandra CG, P.H.V. Sai ST, (2020) Experimental study on density and thermal conductivity properties of Indian coal fly ash water-based nanofluid. Int J Ambient Energy $1: 1-14$

31. Kanti P, Sharma KV, Ramachandra CG, Azmi WH (2021) Experimental determination of thermophysical properties of Indonesian fly-ash nanofluid for heat transfer applications. Particulate Scie Technol 39(5):597-606

32. Kanti P, Sharma KV, Revanasiddappa M, Ramachandra CG, S. Akilu S, (2020) Thermophysical properties of fly ash-Cu hybrid nanofluid for heat transfer applications. Heat Transfer 1:1-16

33. Kanti P, Sharma KV, Ramachandra CG, Panitapu B (2020) Stability and thermophysical properties of fly ash nanofluid for heat transfer applications. Heat Trans 49:4722-4737

34. Lan K, Shang S, Guo C, Xiong T, Qin Z, He W, Li J (2019) Preparation of fly ash nickel catalyst and its application in catalytic pyrolysis of rice straw for syngas production. BioRes 14(3):6983-7000

35. Wang N, Chen J, Zhao Q, Xu H (2017) Study on preparation conditions of coal fly ash catalyst and catalytic mechanism in a heterogeneous Fenton-like process. RCS Advances 7(83):52524-52532

36. Thirunarayanan G, Mayavel P, Thirumurthy K (2012) Fly-ash: $\mathrm{H}_{2} \mathrm{SO}_{4}$ catalyzed solvent free efficient synthesis of some aryl chalcones under microwave irradiation. Spectrochimica Acta Part A: Molecular and Biomol Spectrosc 91:18-22

37. Al-Zeer MIM, MacKenzie KJD (2019) Fly Ash based geopolymers as sustainable bifunctional heterogeneous catalysts and their reactivity in Friedel-Crafts acylation reactions. Catalysts 9:372

38. Zhang Al, Wang NN, Zhou JT, Jiang P, Liu GF (2012) Heterogeneous Fenton-like catalytic removal of $p$-nitrophenol in water using activated fly ash. J Hazard Mater 201-202:68-73

39. Wang S (2008) Application of solid ash based catalysts in heterogeneous catalysis. Environ Sci Technol 42(19):7055-7063

40. Chigondo M, Guyo U, Shumba M, Chigondo F, Nyamunda B, Moyo M, Nhongo T (2013) Synthesis and characterization of zeolites from coal fly ash. Int Res Association of Comput Sci Technol IRACST Eng Sci Technol-An Int J (ESTIJ) 3(4):714-718

41. Sullivan JM, Willard JW, White DL, Kim YK (1983) Production of oxalic acid via the nitric acid oxidation of hardwood (Red Oak) sawdust. Ind Eng Chem Prod Res Dev 22(4):699
42. Oghome PI, Amanze KO, Kamalu CIO, Nkwocha AC, Opebiyi SO (2012) Comparative analysis of oxalic acid produced from rice husk and paddy. Int J Eng Sci Technol (IJEST) 4(9):4196

43. Smith TN, Hash K, Davey CL, Mills H, Williams H, Kiely DE (2012) Modifications in the nitric acid oxidation of glucose. Carbohydr Res 350:6-13

44. Aslam AM, Sproull RD, Laver ML, Biermann CJ (1989) The utilization of Douglas-fir bark for the production of oxalic acid and high density carbon pellets. Appl Biochem Biotech 20(21):135-148

45. Hu F, Ragauskas A (2014) Suppression of pseudo-lignin formation under dilute acid pretreatment conditions. RSC Adv 4(9):4317-4323

46. Baugh KD, McCarty I (1988) Thermochemical pretreatment of lignocellulose to enhance methane fermentation: Monosaccharide and furfurals hydrothermal decomposition and product formation rates. Biotechnol Bioeng 31(1):50-61

47. Guvenatam B, Heeres EHJ, Pidko EA, Hensen EJM (2016) Lewisacid catalyzed depolymerization of Protobind lignin in supercritical water and ethanol. Catalysis Today 259:460-466

48. Rahimi A, Azarpira A, Kim H, Ralph J, Stahl SS (2013) Chemoselective metal-free aerobic alcohol oxidation in lignin. J Am Chem Soc 135(17):6415-6418

49. Gasson JR, Forchheim D, Sutter T, Hornung U, Kruse A, Barth T (2012) Modeling the lignin degradation kinetics in an ethanol/ formic acid solvolysis approach Part 1 kinetic model development. Ind Eng Chem Res 51(32):10595-10606

50. Bond GC, Thompson DT (1999) Catalysis by gold. Catal Rev Sci Eng 41(3-4):319-388

51. Mane JD, Modak HM, Ramaiah NA, Jadhav SJ (1988) Utilisation of sugarcane trash and other cellulosic wastes for production of oxalic acid. Biological Wastes 25(3):171-176

Publisher's Note Springer Nature remains neutral with regard to jurisdictional claims in published maps and institutional affiliations. 